\title{
Beclin 1 acetylation impairs the anticancer effect of aspirin in colorectal cancer cells
}

\author{
Ting Sun ${ }^{1,2, *}$, Liang Ming ${ }^{1,2, *}$, Yunmeng Yan ${ }^{1,2, *}$, Yan Zhang ${ }^{1,2}$ and Haikuo Xue ${ }^{1,2}$ \\ ${ }^{1}$ Key Clinical Laboratory of Henan Province, Department of Clinical Laboratory, The First Affiliated Hospital of Zhengzhou \\ University, Zhengzhou 450052, China \\ ${ }^{2}$ Department of Medical Laboratory, Zhengzhou University, Zhengzhou 450001, China \\ *These authors have contributed equally to the work \\ Correspondence to: Liang Ming, email: mingliangzzu@163.com \\ Keywords: aspirin, autophagy, Beclin 1, acetylation, colorectal cancer
}

Received: May 19, $2017 \quad$ Accepted: July 25, $2017 \quad$ Published: August 19, 2017

Copyright: Sun et al. This is an open-access article distributed under the terms of the Creative Commons Attribution License 3.0 (CC BY 3.0), which permits unrestricted use, distribution, and reproduction in any medium, provided the original author and source are credited.

\section{ABSTRACT}

Regular use of aspirin can reduce cancer incidence, recurrence, metastasis and cancer-related mortality. Aspirin suppresses proliferation and induces apoptosis and autophagy in colorectal cancer cells, but the precise mechanism is not clear. In this study, we demonstrated that aspirin induced autophagosome formation in colorectal cancer cells, but autophagic degradation was blocked through aspirin-mediated Beclin 1 acetylation. Blocked autophagic degradation weakened aspirin-induced cell death. Collectively, our findings indicate the dual roles of aspirin on autophagy, and demonstrate a new mechanism by which Beclin 1 acetylation impairs the anticancer effect of aspirin in colorectal cancer cells.

\section{INTRODUCTION}

Aspirin, a nonsteroidal anti-inflammatory drug (NSAID), is widely used as a painkiller, antipyretic or antiplatelet agent for more than 100 years [1]. In addition to its classical anti-inflammatory function, epidemiological studies in several trials have demonstrated that prolonged aspirin use reduces cancer risk, particularly colorectal cancer (CRC) [2-7], indicating a promising role of aspirin for cancer prevention [8-10]. Although evidence of aspirin's anticancer effect is compelling, the underlying molecular mechanism remains enigmatic.

Aspirin consists of acetyl and salicylate moieties. While the salicylate group implicates in the antiinflammatory and anti-cancer properties via targeting cyclin A2/CDK2, HMGB1 and NF- $\mathrm{BB}$ pathway [11-13], the acetyl group causes the inactivation of cyclooxygenases (COXs) through acetylation of serine residues [14]. While aspirin's ability to acetylate and inhibit COXs enzyme activity is well known [14], multiple cellular proteins can be acetylated by aspirin, suggesting that aspirin may exert its anticancer effect by acetylating multiple cellular targets $[15,16]$.
Substantial evidence indicates aspirin induces apoptosis and autophagy [17-19]. Autophagy is a highly conserved self-digestion process, during which useless cytoplasmic components, such as protein aggregates, damaged organelles, are sequestered into double-membraned structures called autophagosomes. Autophagosomes then fuse with lysosomes for subsequent degradation [20-22]. Beclin 1 is an essential autophagy effector. Our previous study has confirmed that Beclin 1 acetylation inhibits autophagosome maturation and promotes tumor growth [23].

In this study, we investigated the effect of aspirin on Beclin 1 acetylation and autophagy in CRC cells, providing new insight into aspirin for cancer therapy.

\section{RESULTS}

Aspirin induces autophagosome formation in colorectal cancer cells

Substantial evidence indicates that aspirin inhibits cell proliferation. A recent publication shows that aspirin inhibits cell proliferation through downregulation of c-myc gene expression in HCT116 cells [24]. In our 
study, the antiproliferative activity of aspirin on CRC cells was investigated by CCK-8 assay. Treatment of HCT116 and SW480 cells with varying concentrations of aspirin resulted in significantly reduced survival of cells in a concentration-dependent manner (Figure 1A). These results confirmed the potential cytotoxic effect of aspirin in CRC cells.

Previous study indicates aspirin could induce apoptosis $[25,26]$. We assessed the effect of aspirin on the expression of apoptosis marker PARP. Cleavage of PARP was observed in HCT116 and SW480 cells after aspirin treatment, confirming induction of apoptosis by aspirin (Figure 1B, 1C). Previous study has proved that aspirin inhibits mTOR, activates AMPK, and induces autophagy in colorectal cancer cells [19]. We also confirmed this in our study. LC3 is a commonly used autophagy marker and its processed form, LC3 I, resides in cytoplasm. After autophagy induction, LC3 II, the conjugated form of LC3, associates with autophagosomes. Substantial up-regulation of LC3 II was observed in HCT116 and SW480 cells after aspirin treatment (Figure 1B, 1C). We also investigated aspirin's effects on the activity of mTORC1 and AMPK. ACC (acetyl-CoA carboxylase) is one direct downstream target of AMPK. There was a striking decrease in the mTORC1 target protein S6K phosphorylation, while phosphorylation of AMPK and ACC was increased after aspirin treatment, confirming aspirin induces AMPK activation and mTOR inhibition in CRC cells (Figure 1B, 1C).

Aspirin-induced autophagy induction was further confirmed by immunofluorescence. HCT116 and SW480 cells were transfected with GFP-LC3, a highly specific fluorescent marker of autophagy, to measure autophagosome formation. We also use Earle's balanced salt solution (EBSS) to mimic the nutrient-starvation condition to induce autophagy. Aspirin increased GFP-
A

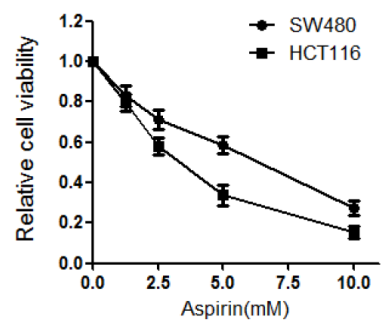

D

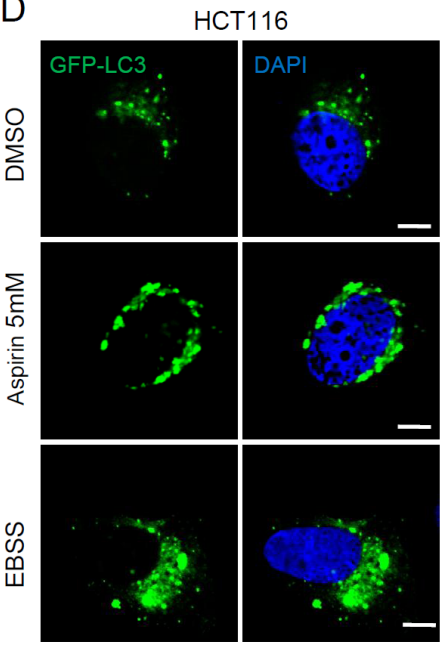

B

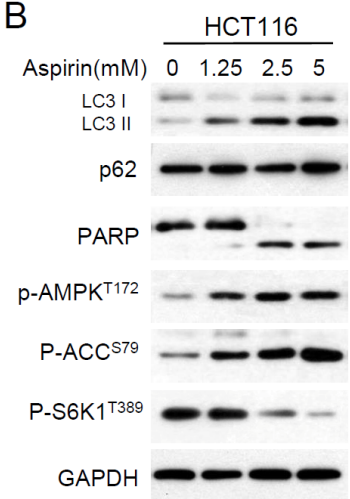

E

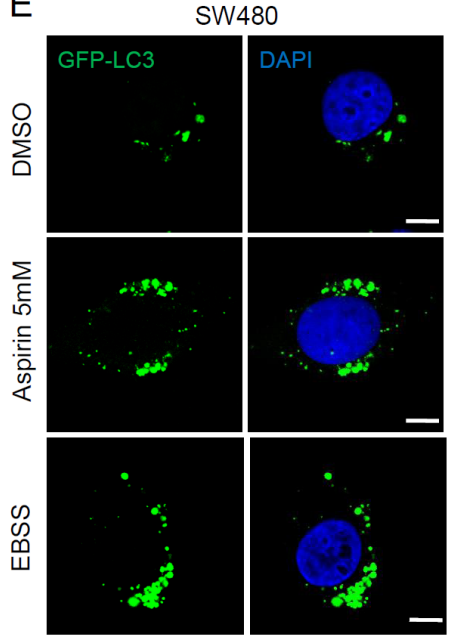

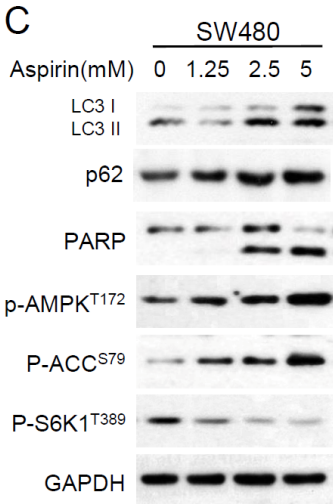

$\mathrm{F}$

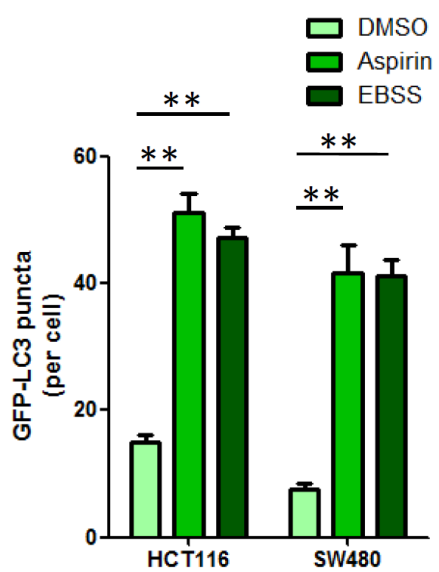

Figure 1: Aspirin inhibited proliferation and induced autophagy in HCT116 and SW480 cells. (A) Cell viability was determined by CCK 8 assay after aspirin treatment at various concentrations $(0,1.25,2.5,5,10 \mathrm{mM})$ for $72 \mathrm{~h}$. Bars represent mean $\pm \mathrm{SEM}$. Three independent experiments (n=3). (B-C) HCT116 and SW480 cells were treated with different concentration of aspirin for $24 \mathrm{~h}$. Protein levels were estimated using western blot analysis. GAPDH was used as loading control. (D-E) HCT116 and SW480 cells were transfected with GFP-LC3 plasmid for $24 \mathrm{~h}$. Then the cells were treated with $5 \mathrm{mM}$ aspirin or DMSO for $24 \mathrm{~h}$ or EBSS for $4 \mathrm{~h}$, followed by confocal fluorescence microscopy. Scale bar, $5 \mu \mathrm{m}$. Data represents three independent experiments. (F) Quantitation of GFP-LC3 puncta in D and E. Bar are mean $\pm \mathrm{SEM}$ of 50 cells; three independent experiments, $* * \mathrm{P}<0.01$ (Student's t-test). 
LC3 puncta significantly, just as EBSS did, confirming autophagosome formation was induced by aspirin in CRC cells (Figure 1D-1F).

\section{Aspirin inhibits autolysosome degradation in colorectal cancer cells}

Autophagy is a highly dynamic, multi-step process, including autophagosome formation, maturation, fusion with lysosomes and degradation [27]. Therefore, an increase in autophagosomes alone, does not necessarily indicate increased autophagy flux [28]. p62 is a polyubiquitin-binding protein which contains a LC3interacting motif and an ubiquitin-binding domain. By linking ubiquitinated substrate with autophagic machinery, p62 is incorporated in completed autophagosomes and degraded in autolysosomes, together with its bound proteins [29]. As shown in Figure 1B and 1C, p62 was not degraded in aspirin-induced autophagy. It suggested that autophagy-mediated clearance of p62 was blocked.

Bafilomycin A1 (BafA1), a vacuolar H+-ATPase inhibitor, inhibits the degradation of autophagosomes by preventing lysosome function [30]. EBSS induced the conversion of LC3 I to LC3 II and downregulation of p62 in HCT116 cells, and the accumulation of LC3 II was further enhanced by bafilomycin A1. Bafilomycin A1 also restored the downregulation of p62 (Figure 2A).
Therefore EBSS induces a true increase in autophagic flux. However, things were different in aspirin inducedautophagy. Aspirin induced the accumulation of LC3 II but not the downregulation of p62 in HCT116 cells. And bafilomycin A1 nearly had no effect on the aspirin-induced accumulation of LC3 II (Figure 2B).

We also examined the intracellular morphologic change of HCT116 cells by using transmission electron microscopy. Electron microscopy analysis showed that many autophagosomes accumulated in aspirin-treated cells, while autolysosomes were relatively rare. But in EBSS-treated cells, autophagosomes and autolysosomes were observed simultaneously (Figure 2C, 2D). In conclusion, these findings indicated that aspirin induces autophagosome formation but these autophagosomes can not fusion with lysosomes and degradation.

\section{Aspirin promotes acetylation of Beclin 1}

Our previous study has proved that Beclin 1 can be acetylated by acetyltransferase p300, and Beclin 1 acetylation inhibits autophagosome maturation and degradation by promoting the binding of Rubicon to Beclin 1 [23]. Evidence also shows that aspirin promotes p300-mediated acetylation of COMMD1 [31]. So we investigated whether aspirin affects the acetylation of Beclin 1 to inhibit autophagic degradation. Firstly, we
A

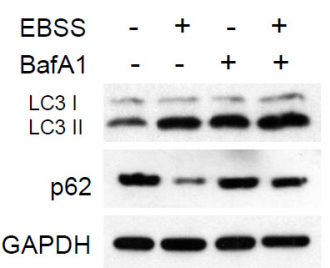

C

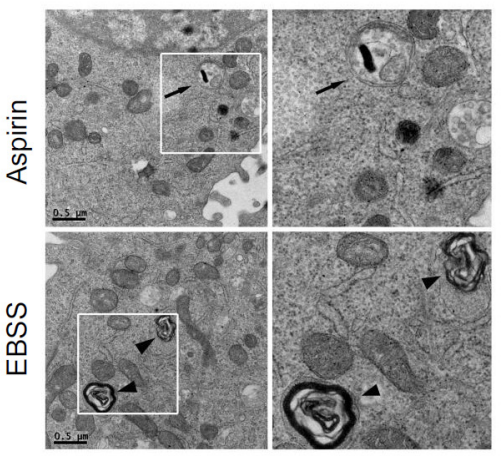

$\mathrm{B}$
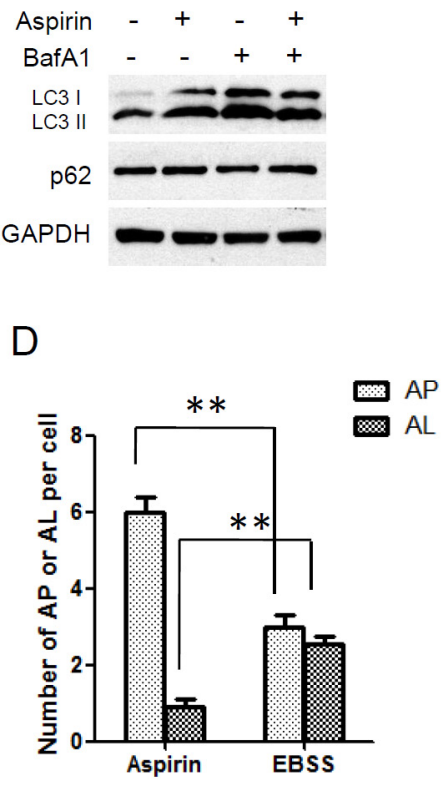

Figure 2: Autophagic degradation was blocked in aspirin treated SW480 cells. (A) HCT116 cells were treated with EBSS for $4 \mathrm{~h}$ after cells were pretreated with $100 \mathrm{nM}$ Bafilomycin A1 for $2 \mathrm{~h}$. (B) HCT116 cells were treated with aspirin $5 \mathrm{mM}$ for $24 \mathrm{~h}$ after cells were pretreated with $100 \mathrm{nM}$ BafilomycinA1 for $2 \mathrm{~h}$. Levels of LC3 and p62 were evaluated by western blotting. GAPDH was used as loading control. (C) Electron microscopy analysis of autophagosomes and autolysosomes. HCT116 cells treated with EBSS or Aspirin were subjected to electron microscopy analysis. The arrows indicate autophagosomes (AP) and the arrowheads indicate autolysosomes (AL). Scale bar, $0.5 \mu \mathrm{m}$. (D) Quantitation of AP and AL in HCT116 cells as in C. Bar are mean \pm SEM of 20 cells; three independent experiments, $* * \mathrm{P}<0.01$ (Student's t-test). 
examined the effect of aspirin on protein expression of Beclin 1. The protein levels of Beclin 1 did not change with aspirin treatment in HCT116 cells (Figure 3A). Then the acetylation level of endogenous Beclin 1 was detected by using an anti-acetylated lysine antibody. We found that acetylation of Beclin 1 was significantly increased after treating cells with aspirin (Figure 3B). Moreover, HCT116 cells were transiently transfected with flag-tagged Beclin 1. Similar experiments with ectopically expressed Beclin 1 also showed that aspirin enhances Beclin 1 acetylation and the binding of Beclin 1 to p300 and Rubicon (Figure 3C). To further validate our finding, we knocked down p300 by target siRNA or blocked p300 activity with inhibitor C646. p300 knockdown decreased Beclin 1 acetylation and the interaction with Rubicon induced by aspirin. Similar effects were observed when p300 was inhibited by $30 \mu \mathrm{M}$ C646 (Figure 3D).
Our previous study has confirmed that Beclin 1 is acetylated by p300 at lysine 430 and lysine 437 [23]. The acetylation sites on Beclin 1 were first identified by mass spectrometry and site-directed mutagenesis of Beclin 1 was performed. We mutated each or both lysine $(\mathrm{K})$ to arginine (R), each single mutation resulted in a weak reduction in Beclin 1 acetylation, whereas the double mutation (2KR) resulted in a significant decrease in Beclin 1 acetylation, indicating that Beclin 1 can be acetylated at the site Lys430 and Lys437. In this study, we investigated whether aspirin-mediates Beclin 1 acetylation was on the same amino acid residues. Beclin 1 lysines 430 and 437 were mutated to arginine (2KR). We then transfected wildtype or $2 \mathrm{KR}$ mutant Beclin 1 into HCT116 cells. Aspirin increased the acetylation of wild-type but not $2 \mathrm{KR}$ mutant Beclin 1. Correspondingly, aspirin also resulted in the enhanced interaction of Rubicon with WT but not

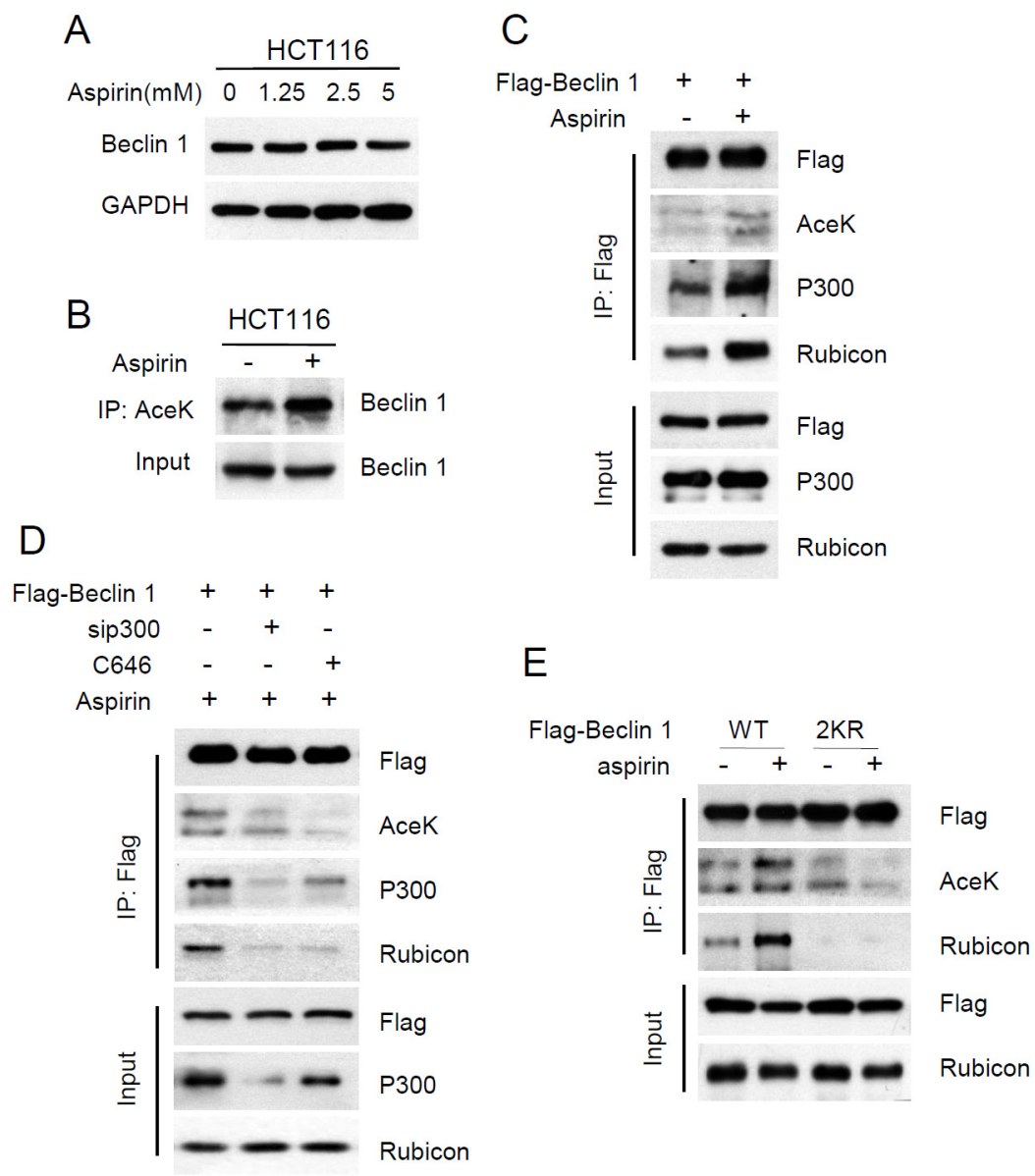

Figure 3: Aspirin enhanced p300-mediated Beclin 1 acetylation on lysine 430 and 437. (A) HCT116 cells were treated with different concentration of aspirin for $24 \mathrm{~h}$. Protein levels of Beclin 1 were estimated using western blot analysis. GAPDH was used as loading control. (B) Acetylated proteins were immunoprecipitated with the antibody to acetylated lysine from HCT116 cells after aspirin treatment. Acetylation of endogenous Beclin 1 protein was analyzed with western bolt. (C) Flag-tagged Beclin 1 was transfected into HCT116 cells. Then the transfected cells were treated with DMSO or 5mM aspirin for $24 \mathrm{~h}$. Acetylation of exogenous Beclin 1 protein was analysed with IP and western bolt. (D) Flag-tagged Beclin 1 was transfected into HCT116 cells, in another group, flag-tagged Beclin 1 was co-transfected with sip300. Then the transfected cells were treated with aspirin DMSO or C646. (E) Flag-tagged Beclin 1 (WT, 2KR) was

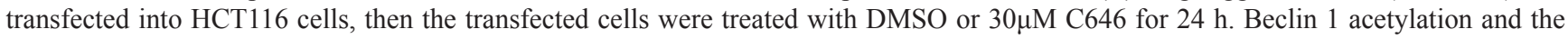
interaction between Beclin 1 and p300 or Rubicon was determined with IP and western blot analyses. 
with the 2KR mutant Beclin 1 (Figure 3E). These findings indicate that aspirin promotes p300-mediated Beclin 1 acetylation at lysines 430 and 437 in CRC cells.

\section{Aspirin-mediated Beclin 1 acetylation inhibits autophagic degradation}

Aspirin-mediated Beclin 1 acetylation enhanced the binding of Beclin 1 with Rubicon, which is a negative regulator for autophagosome maturation and degradation $[32,33]$. To further assess the effect of Beclin 1 acetylation on aspirin induced autophagy, we performed western blot analysis of p62 and LC3. HCT116 and SW480 cells were treated with aspirin or together with p300 inhibitor C646. We found that combination with C646 released the block of p62 degradation induced by aspirin and the accumulation of LC3 II was also attenuated slightly. However, Beclin 1 protein expression did not change in various treatments (Figure 4A, 4B). We also assess the different effect of aspirin on autophagic degradation in

wildtype or the 2KR mutant Beclin 1 expressing HCT116 cells. After aspirin treatment, p62 was not degraded in cells expressing Beclin 1 WT, but degradation of p62 was accelerated in the Beclin 1-2KR expressing cells. And the accumulation of LC3 II was higher in WT Beclin 1 expressing cells (Figure 4C). These findings indicated that aspirin-mediated Beclin 1 acetylation inhibits p62 degradation in lysosomes.

Furthermore, tandem fluorescent mCherry-EGFPLC3 was designed to monitor autophagic flux. The EGFP signal is acid sensitive and quenched quickly following fusion with lysosomes, whereas mCherry is relatively stable. Therefore, colocalization of both EGFP and mCherry fluorescence indicates an early autophagosome (yellow) and an mCherry signal only corresponds to an autolysosome (red) [34]. Before treatment with aspirin, only weak signals of EGFP and mCherry which represent diffuse LC3 protein were found in the cytoplasm. After treatment with aspirin, a large number of yellow puncta was observed in the perinuclear region, suggesting the
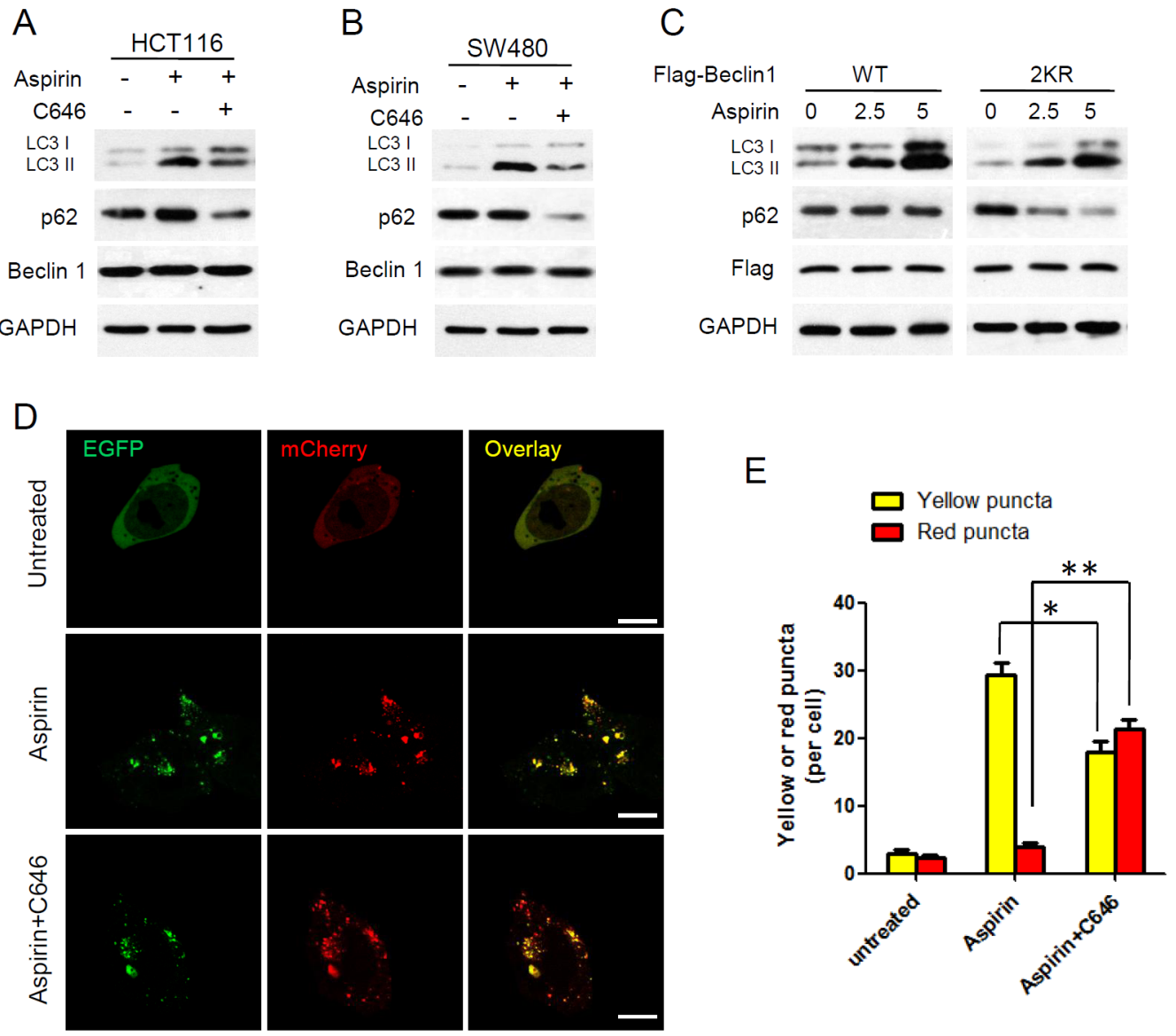

Figure 4: Aspirin-mediated Beclin 1 acetylation inhibits autophagic degradation. (A-B) HCT116 and SW480 cells were

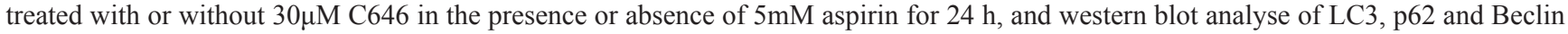
1 were performed. (C) Flag-tagged Beclin 1 (WT, 2KR) was transfected into HCT116 cells, then the transfected cells were treated with different concentration of aspirin for $24 \mathrm{~h}$. Western blot analyses of LC3 and p62 were performed. (D) HCT116 cells transfected with mCherry-EGFP-LC3 were treated with or without 30 $\mathrm{M}$ C646 in the presence of 5mM aspirin for $24 \mathrm{~h}$. Scale bars, $5 \mu \mathrm{m}$. (E) Quantitation of red and yellow puncta in D. Bars represent mean \pm SEM of 50 cells; three independent experiments, ${ }^{*} \mathrm{P}<0.05$, ${ }^{* *} \mathrm{P}<0.01$ (Student's t-test). 
formation of autophagosomes, but red puncta were relatively rare. When combination C646 with aspirin, more red puncta were observed than aspirin treated only (Figure 4D, 4E). It suggested that C646 promotes autophagosomes develop maturing to autolysosome in aspirin treated cells.

Taken together these findings indicated that degradation is blocked by Beclin 1 acetylation in aspirininduced autophagy, and p300 inhibitor releases the block of autophagic degradation.

\section{Inhibition of Beclin 1 acetylation enhances aspirin cytotoxic effect in CRC cells}

To further determine the effect of Beclin 1 acetylation on aspirin-induced apoptosis, we inhibited Beclin 1 acetylation by C646 in aspirin treated CRC cells. Combination with $\mathrm{C} 646$ resulted in more cleavage of PARP than aspirin only in HCT116 and SW480 cells (Figure 5A, 5B). Aspirin also induced more cleavage of PARP in the Beclin 1-2KR expressing cells than cells expressing wide-type Beclin 1 (Figure 5C). Annexin V/ PI apoptosis assay was performed by flow cytometer. Combination C646 with aspirin resulted in obviously more apoptosis in HCT116 and SW480 cells than aspirin treatment only and C646 itself nearly induced no apoptosis in CRC cells (Figure 5D, 5E). It is worth noting that combination C646 with aspirin resulted in some nonapoptotic cell death (Annexin V-/PI+). These findings suggested that, besides apoptosis, autophagy also takes part in the aspirin-mediated cell death in CRC cells.

We next evaluated the role of Beclin 1 acetylation on antitumor efficacy of aspirin. We found that inhibiting Beclin 1 acetylation by C646 potentiated the cytotoxic effect of aspirin in HCT116 and SW480 cells (Figure 5F, $5 \mathrm{G})$. These results suggested that Beclin 1 acetylation acts as a pro-survival mechanism in aspirin induced cell death and unrestricted autophagic degradation enhances the antitumor efficacy of aspirin in CRC cells.

\section{DISCUSSION}

Considerable interest has emerged over the last decade regarding the role of aspirin in prevention of CRC [35-37]. Besides inhibition of COX, aspirin has a diversity of tumor suppressive effects through COX-independent mechanisms [38-40]. Despite a lot of epidemiological
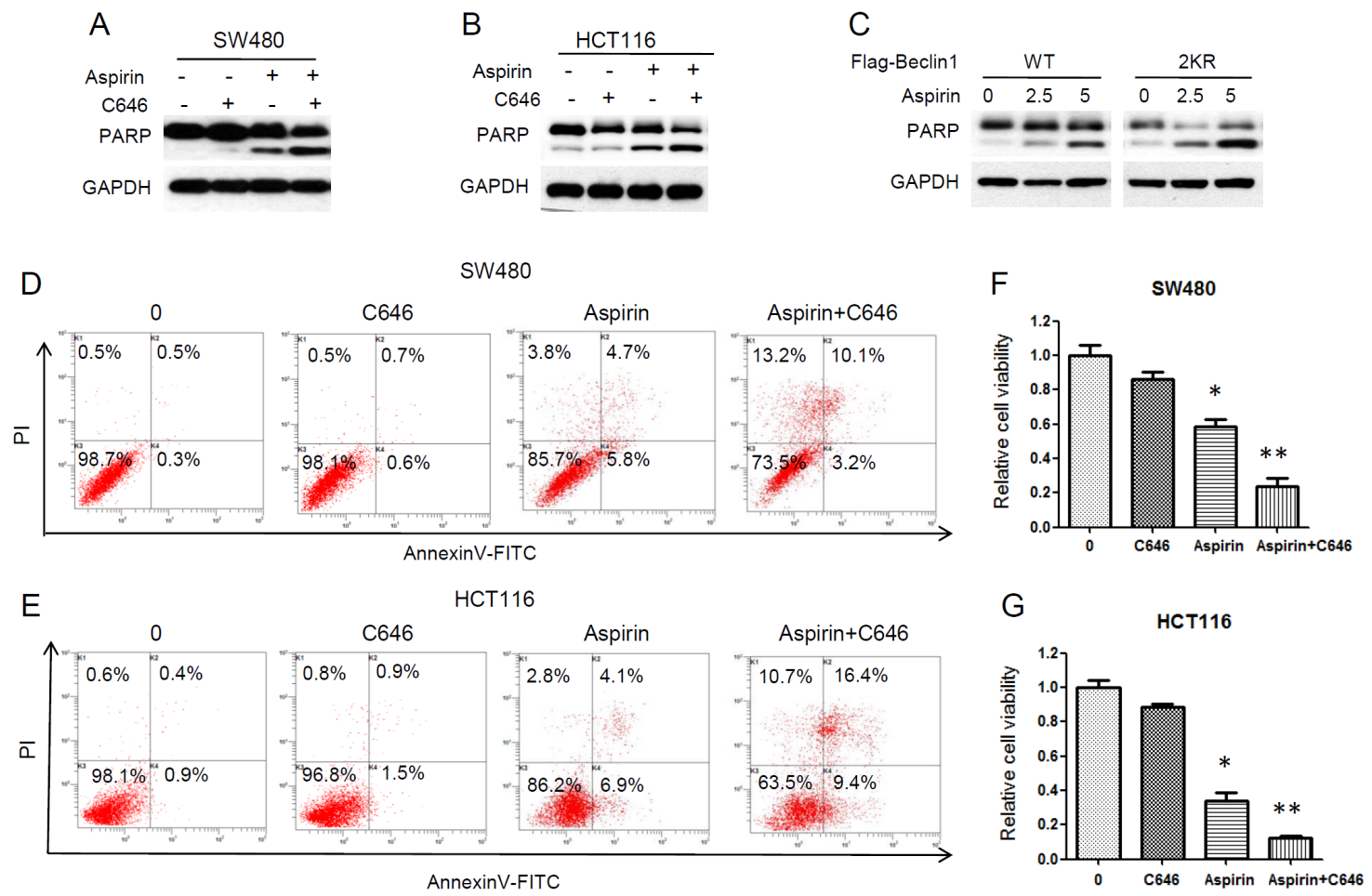

Figure 5: Inhibition of Beclin 1 acetylation by C646 promoted aspirin-induced cell death. (A-B) HCT116 and SW480 cells were treated with or without $30 \mu \mathrm{M}$ C646 in the presence or absence of $5 \mathrm{mM}$ aspirin for $24 \mathrm{~h}$, and western blot analyse of PARP was performed. (C) Flag-tagged Beclin 1 (WT, 2KR) was transfected into HCT116 cells, then the transfected cells were treated with different concentration of aspirin for $24 \mathrm{~h}$. Western blot analyse of PARP was performed. (D-E) Flow cytometric assay with Annexin V-FITC/PI double staining. HCT116 and SW480 cells were treated with or without $30 \mu \mathrm{M} \mathrm{C646} \mathrm{in} \mathrm{the} \mathrm{presence} \mathrm{of} 5 \mathrm{mM}$ aspirin for $24 \mathrm{~h}$, stained with AnnexinV-FITC and PI, then measured by flow cytometer. (F-G) HCT116 and SW480 cells were treated with 5mM aspirin with or without $30 \mu \mathrm{M}$ C646 for $72 \mathrm{~h}$. Cell viability was then determined using CCK-8 assays. Bars represent mean \pm SEM. Three independent experiments. $* \mathrm{P}<0.05$, ${ }^{*} \mathrm{P}<0.01$ (Student's t-test). 
and preclinical studies that test the tumor suppressive role of aspirin, little is known about the roadblocks that counteract the anticancer effect of aspirin.

Studies over the past decades suggest that aspirin acetylates many cellular proteins $[15,16]$. Since posttranslational modification of proteins, such as acetylation, may lead to the alteration of their function, it is possible that some of the hitherto unexplained therapeutic properties of aspirin may occur as a result of these modifications. The identification of these novel acetylation targets of aspirin represents a new area for investigation. In this study, we demonstrate for the first time that aspirin acetylated Beclin 1 in HCT116 and SW480 colorectal cancer cells. Thus, our finding extends the previously known list of proteins acetylated by aspirin suggesting that the acetylation of proteins may be a major factor involved in some of the unexplained effects of aspirin.

The ability of aspirin to trigger apoptosis in cancer cells is well known. Besides apoptosis, autophagy is frequently reported to be induced by many antitumor agents. Farhat V.N. Din et al reported that aspirin induces autophagy in colorectal cancer cells through AMPK activation and mTOR inhibition. In this study, we found that aspirin induces autophagosomes formation, but the autophagosome induced by aspirin can not go through to degradation in lysosomes. Aspirin-mediated Beclin 1 acetylation inhibited autophagosome degradation, then weakened the aspirin-induced cell death in CRC cells (Figure 6). On the contrary, the complete autophagic flux enhanced the cytotoxicity of aspirin in CRC cells. These findings indicate that Beclin 1 acetylation serves as the roadblock that counteract the anticancer effect of aspirin.

Aspirin is also known as acetylsalicylic acid (ASA), with salicylic acid serving as the important active metabolite. Our study shows that aspirin-mediated Beclin 1 acetylation impairs the anticancer effect of aspirin in colorectal cancer cells. In order to clarify whether the observed effects are due to acetylation effect of aspirin rather than function of salicylate group. We confirmed autophagy occurrence and Beclin 1 acetylation by use of salicylic acid. We found that salicylic acid induced the conversion of LC3 I to LC3 II and downregulation of p62 in HCT 116 and SW480 cells. It suggested that salicylic acid induced autophagy and autophagic degradation was not blocked in CRC cells (Supplementary Figure 1A, 1B). We also investigated whether salicylic acid affects the acetylation of Beclin 1 just as aspirin did. But salicylic acid had no effect on Beclin 1 acetylation, either endogenous or exogenous (Supplementary Figure 1C, 1D). In addition, combination with $\mathrm{C} 646$ could restore the anticancer effect of aspirin in CRC cells (Figure 5D$5 \mathrm{G})$. These findings indicate that acetylation effect of aspirin rather than function of salicylate group blocks the autophagic degradation and impairs the anticancer effect of aspirin.

Autophagy is thought to play dual roles in cancer [41]. And autophagy is a dynamic and multi-step process. Every step in autophagy flux can be mediated by multiple signaling pathway. Therefore, the study of the detailed molecular mechanisms underlying autophagy is crucial for

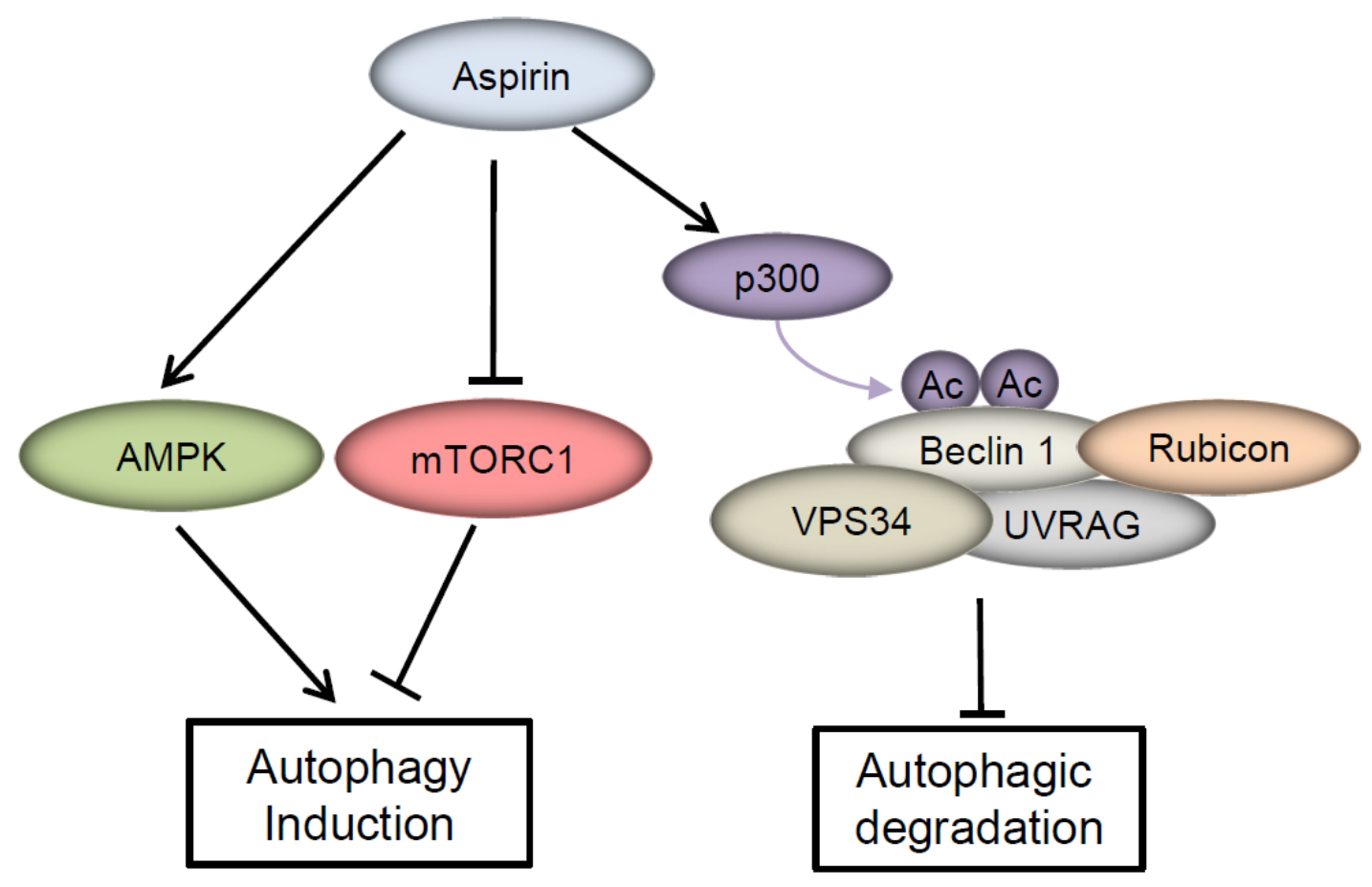

Figure 6: A model of the molecular linkage between aspirin, Beclin 1 acetylation and autophagy. 
cancer control. Many studies have shown that autophagy can contribute to apoptosis $[42,43]$. In our study, we found that complete autophagic flux enhances aspirin-induced apoptosis, but it also resulted in cell death apoptosis in dependent. These findings suggested that autophagymediated cell death also takes part in the antitumor effect of aspirin in CRC cells.

In conclusion, our study provides a new insight into effect of aspirin in colorectal cancer cells. Aspirinmediated Beclin1 acetylation inhibits autophagosome maturation and degradation, suggesting that the initiationinducing and degradation-blocking functions of aspirin are worth further exploration for cancer therapy.

\section{MATERIALS AND METHODS}

\section{Cell culture}

The colorectal cancer cell line HCT116 and SW480 were obtained from Cell Lines Bank, Chinese Academy of Science (Shanghai, China). HCT116 cells were cultured in McCoy's 5A and SW480 cells were cultured in DMEM medium, supplemented with $10 \%$ fetal bovine serum (Gibco, Grand Island, NY, USA), $100 \mathrm{mg} / \mathrm{mL}$ penicillin and $100 \mathrm{mg} / \mathrm{mL}$ streptomycin. The cells were incubated at $37^{\circ} \mathrm{C}$ in a humidified atmosphere containing $5 \% \mathrm{CO} 2$.

\section{Antibodies and reagents}

Anti-Beclin 1, acetylated lysine, PARP, p-AMPK $\alpha$ (T172), p-ACC (S79) and p-S6K1 (T389) antibodies were obtained from Cell Signaling Technology (Danvers, MA, USA). Anti-LC3 antibody was obtained from NOVUS (Littleton, CO, USA). Anti-Rubicon antibody was obtained from Abcam (Cambridge, MA, USA). Anti-p300, p62/SQSTM1 and GAPDH antibodies were obtained from Santa Cruz Biotechnology (Santa Cruz, CA, USA). AntiFlag antibody, aspirin, salicylic acid, Bafilomycin A1 and C646 were purchased from Sigma Aldrich (St. Louis, MO, USA).

\section{Western blotting and immunoprecipitation}

Whole-cell extracts were generated by direct lysis with $1 \times$ Cell Lysis Buffer (Cell Signaling Technology) adding $1 \mathrm{mM}$ phenylmethylsulphonyl fluoride (PMSF) immediately before use. Samples were boiled by addition $5 \times$ SDS sample buffer for $10 \mathrm{~min}$ at $100^{\circ} \mathrm{C}$ and resolved using SDS-PAGE. For immunoprecipitation, cells were lysed by E1A lysis buffer (250mM NaCl, 50mM HEPES (pH 7.5), 0.1\% NP-40, 5mM EDTA, protease inhibitor cocktail (Roche)). For acetylation immunoprecipitation, $2 \mathrm{mM}$ TSA and 10mM NAM were added. Cell lysates were mixed with FLAG beads at $4^{\circ} \mathrm{C}$ overnight. Immunoprecipitates were washed three times with cold lysis buffer and eluted with SDS loading buffer by boiling for $10 \mathrm{~min}$. The proteins were resolved by SDS-PAGE and then transferred onto PVDF membranes, which were blocked in 5\% (w/v) nonfat milk and hybridized with specific primary antibodies. The resulting protein bands were visualized using ECL after hybridization with a secondary antibody.

\section{Plasmids and transfection}

The following Addgene plasmids were used: Addgene plasmid 22,418 (mCherry-EGFP-LC3B) and Addgene plasmid 22,405 (GFP-LC3). Flag-Beclin1 was constructed by cloning Beclin 1 into pcDNA3 vector. Site-directed mutagenesis of flag-Beclin 1 was performed using QuikChange XL (Stratagene). Plasmid transient transfection was performed using Lipofectamine 2,000 according to manufacturer's instructions.

\section{RNA interference}

Target siRNA was produced by GenePharma (Suzhou, China) and transfected using Lipofectamine RNAiMAX Transfection Reagent (life Technologies) according to the manufacturer's protocol. Target sequence as follows:

p300 (5'-CAGACAAGTCTTGGCATGGTA-3'),

\section{Autophagy analysis}

Autophagy was measured by quantitation of LC3 puncta using fluorescence microscopy. Cells were plated in a 24-well plate on a coverslip and allowed to attach overnight. Cells were infected with appropriate amounts of plasmids GFP-LC3 or mCherry-EGFP-LC3. After aspirin treatment, cells were fixed with 4\% paraformaldehyde for 20 min and rinsed with PBS twice. Cells were mounted and visualized under a confocal microscope (Olympus FV$1,000)$. Total number of cells on images was determined by nuclei staining with DAPI.

\section{Transmission electron microscopy}

Cells were collected and fixed after different treatment. The ultrathin $50 \mathrm{~nm}$ sections were cut by use of an ultramicrotome, stained with $2 \%(\mathrm{w} / \mathrm{v})$ uranyl acetate and lead citrate, then examined with electron microscope Hitachi 600 (Hitachi, Japan).

\section{Flow cytometric analysis of apoptosis}

Apoptotic rate was detected by flow cytometry with the Annexin V-fluorescein isothiocyanate (FITC) apoptosis detection kit (BD). Briefly, cells were collected after different treatment and the assay were performed according to the manufacturer's instruction. Samples were analyzed immediately using a Cytomics FC500 flow cytometer (Beckman Coulter, Miami, FL, USA). 


\section{Cell viability assay}

HCT116 and SW480 cells were seeded in 96-well plates at a density of 4,000 cells per well. They were treated with different concentrations of Aspirin for 3 days, and the cell viability was measured by CCK- 8 assays.

\section{Statistical analyses}

Student's t-test was used to compare the differences between two groups. $* \mathrm{P}<0.05$ was considered statistically significant and $* * \mathrm{P}<0.01$ as highly significant.

\section{ACKNOWLEDGMENTS}

This research was supported by National Natural Science Foundation of China (Grant No. 31501123) and the Youth Innovation Fund of the First Affiliated Hospital of Zhengzhou University.

\section{CONFLICTS OF INTEREST} interest.

The authors declare that they have no conflicts of

\section{REFERENCES}

1. Vane JR, Flower RJ, Botting RM. History of aspirin and its mechanism of action. Stroke. 1990; 21: IV12-23.

2. Chan AT, Giovannucci EL. Primary prevention of colorectal cancer. Gastroenterology. 2010; 138: 2029-43 e10. https:// doi.org/10.1053/j.gastro.2010.01.057.

3. Sandler RS, Galanko JC, Murray SC, Helm JF, Woosley JT. Aspirin and nonsteroidal anti-inflammatory agents and risk for colorectal adenomas. Gastroenterology. 1998; 114: 441-7.

4. Harris RE, Namboodiri KK, Farrar WB. Nonsteroidal antiinflammatory drugs and breast cancer. Epidemiology. 1996; 7: 203-5.

5. Harris RE, Beebe-Donk J, Alshafie GA. Reduced risk of human lung cancer by selective cyclooxygenase 2 (COX2) blockade: results of a case control study. Int J Biol Sci. 2007; 3: 328-34.

6. McCaffrey P. Aspirin use reduces skin-cancer risk. Lancet Oncol. 2006; 7: 16.

7. Carrat F. Statin and aspirin for prevention of hepatocellular carcinoma: what are the levels of evidence? Clin Res Hepatol Gastroenterol. 2014; 38: 9-11. https://doi. org/10.1016/j.clinre.2013.09.007.

8. Rothwell PM, Fowkes FG, Belch JF, Ogawa H, Warlow $\mathrm{CP}$, Meade TW. Effect of daily aspirin on long-term risk of death due to cancer: analysis of individual patient data from randomised trials. Lancet. 2011; 377: 31-41. https:// doi.org/10.1016/S0140-6736(10)62110-1.
9. Elwood PC, Gallagher AM, Duthie GG, Mur LA, Morgan G. Aspirin, salicylates, and cancer. Lancet. 2009; 373: 13019. https://doi.org/10.1016/S0140-6736(09)60243-9.

10. Thun MJ, Henley SJ, Patrono C. Nonsteroidal antiinflammatory drugs as anticancer agents: mechanistic, pharmacologic, and clinical issues. J Natl Cancer Inst. 2002; 94: 252-66.

11. Dachineni R, Ai G, Kumar DR, Sadhu SS, Tummala H, Bhat GJ. Cyclin A2 and CDK2 as novel targets of aspirin and salicylic acid: a potential role in cancer prevention. Mol Cancer Res. 2016; 14: 241-52. https://doi.org/10.1158/15417786.MCR-15-0360.

12. Kopp E, Ghosh S. Inhibition of NF-kappa B by sodium salicylate and aspirin. Science. 1994; 265: 956-9.

13. Choi HW, Tian M, Song F, Venereau E, Preti A, Park SW, Hamilton K, Swapna GV, Manohar M, Moreau M, Agresti A, Gorzanelli A, De Marchis F, et al. Aspirin's active metabolite salicylic acid targets high mobility group box 1 to modulate inflammatory responses. Mol Med. 2015; 21 : 526-35. https://doi.org/10.2119/molmed.2015.00148.

14. Lecomte M, Laneuville O, Ji C, DeWitt DL, Smith WL. Acetylation of human prostaglandin endoperoxide synthase-2 (cyclooxygenase-2) by aspirin. J Biol Chem. 1994; 269: 13207-15.

15. Wang J, Zhang CJ, Zhang J, He Y, Lee YM, Chen S, Lim $\mathrm{TK}, \mathrm{Ng} \mathrm{S}$, Shen HM, Lin Q. Mapping sites of aspirininduced acetylations in live cells by quantitative acidcleavable activity-based protein profiling (QA-ABPP). Sci Rep. 2015; 5: 7896. https://doi.org/10.1038/srep07896.

16. Marimuthu S, Chivukula RS, Alfonso LF, Moridani M, Hagen FK, Bhat GJ. Aspirin acetylates multiple cellular proteins in HCT-116 colon cancer cells: Identification of novel targets. Int J Oncol. 2011; 39: 1273-83. https://doi. org/10.3892/ijo.2011.1113.

17. Shiff SJ, Koutsos MI, Qiao L, Rigas B. Nonsteroidal antiinflammatory drugs inhibit the proliferation of colon adenocarcinoma cells: effects on cell cycle and apoptosis. Exp Cell Res. 1996; 222: 179-88. https://doi.org/10.1006/ excr.1996.0023.

18. Din FV, Dunlop MG, Stark LA. Evidence for colorectal cancer cell specificity of aspirin effects on NF kappa B signalling and apoptosis. Br J Cancer. 2004; 91: 381-8. https://doi.org/10.1038/sj.bjc.6601913.

19. Din FV, Valanciute A, Houde VP, Zibrova D, Green KA, Sakamoto K, Alessi DR, Dunlop MG. Aspirin inhibits mTOR signaling, activates AMP-activated protein kinase, and induces autophagy in colorectal cancer cells. Gastroenterology. 2012; 142: 1504-15 e3. https://doi. org/10.1053/j.gastro.2012.02.050.

20. Klionsky DJ. Autophagy: from phenomenology to molecular understanding in less than a decade. Nat Rev Mol Cell Biol. 2007; 8: 931-7. https://doi.org/10.1038/nrm2245.

21. Mizushima N. Autophagy: process and function. Genes Dev. 2007; 21: 2861-73. https://doi.org/10.1101/gad.1599207. 
22. Galluzzi L, Pietrocola F, Levine B, Kroemer G. Metabolic control of autophagy. Cell. 2014; 159: 1263-76. https://doi. org/10.1016/j.cell.2014.11.006.

23. Sun T, Li X, Zhang P, Chen WD, Zhang HL, Li DD, Deng R, Qian XJ, Jiao L, Ji J, Li YT, Wu RY, Yu Y, et al. Acetylation of Beclin 1 inhibits autophagosome maturation and promotes tumour growth. Nat Commun. 2015; 6: 7215. https://doi.org/10.1038/ncomms8215.

24. Ai G, Dachineni R, Muley P, Tummala H, Bhat GJ. Aspirin and salicylic acid decrease c-Myc expression in cancer cells: a potential role in chemoprevention. Tumour Biol. 2016; 37 : 1727-38. https://doi.org/10.1007/s13277-015-3959-0.

25. Dikshit P, Chatterjee M, Goswami A, Mishra A, Jana NR. Aspirin induces apoptosis through the inhibition of proteasome function. J Biol Chem. 2006; 281: 29228-35. https://doi.org/10.1074/jbc.M602629200.

26. Gu Q, Wang JD, Xia HH, Lin MC, He H, Zou B, Tu SP, Yang Y, Liu XG, Lam SK, Wong WM, Chan AO, Yuen MF, et al. Activation of the caspase-8/Bid and Bax pathways in aspirin-induced apoptosis in gastric cancer. Carcinogenesis. 2005; 26: 541-6. https://doi.org/10.1093/carcin/bgh345.

27. Tanida I, Minematsu-Ikeguchi N, Ueno T, Kominami E. Lysosomal turnover, but not a cellular level, of endogenous LC3 is a marker for autophagy. Autophagy. 2005; 1: 84-91.

28. Mizushima N, Yoshimori $\mathrm{T}$, Levine B. Methods in mammalian autophagy research. Cell. 2010; 140: 313-26. https://doi.org/10.1016/j.cell.2010.01.028.

29. Saiki S, Sasazawa Y, Imamichi Y, Kawajiri S, Fujimaki T, Tanida I, Kobayashi H, Sato F, Sato S, Ishikawa K, Imoto M, Hattori N. Caffeine induces apoptosis by enhancement of autophagy via PI3K/Akt/mTOR/p70S6K inhibition. Autophagy. 2011; 7: 176-87.

30. Klionsky DJ, Abdelmohsen K, Abe A, Abedin MJ, Abeliovich H, Acevedo Arozena A, Adachi H, Adams CM, Adams PD, Adeli K, Adhihetty PJ, Adler SG, Agam G, et al. Guidelines for the use and interpretation of assays for monitoring autophagy (3rd edition). Autophagy. 2016; 12: 1-222. https://doi.org/10.1080/15548627.2015.1100356.

31. O'Hara A, Simpson J, Morin P, Loveridge CJ, Williams AC, Novo SM, Stark LA. p300-mediated acetylation of COMMD1 regulates its stability, and the ubiquitylation and nucleolar translocation of the RelA NF-kappaB subunit. J Cell Sci. 2014; 127: 3659-65. https://doi.org/10.1242/ jcs.149328.

32. Zhong Y, Wang QJ, Li X, Yan Y, Backer JM, Chait BT, Heintz N, Yue Z. Distinct regulation of autophagic activity by $\operatorname{Atg} 14 \mathrm{~L}$ and Rubicon associated with Beclin 1-phosphatidylinositol-3-kinase complex. Nat Cell Biol. 2009; 11: 468-76. https://doi.org/10.1038/ncb1854.

33. Matsunaga K, Saitoh T, Tabata K, Omori H, Satoh T, Kurotori N, Maejima I, Shirahama-Noda K, Ichimura
T, Isobe T, Akira S, Noda T, Yoshimori T. Two Beclin 1-binding proteins, Atg14L and Rubicon, reciprocally regulate autophagy at different stages. Nat Cell Biol. 2009; 11: 385-96. https://doi.org/10.1038/ncb1846.

34. Klionsky DJ, Abdalla FC, Abeliovich H, Abraham RT, Acevedo-Arozena A, Adeli K, Agholme L, Agnello M, Agostinis P, Aguirre-Ghiso JA, Ahn HJ, Ait-Mohamed O, Ait-Si-Ali S, et al. Guidelines for the use and interpretation of assays for monitoring autophagy. Autophagy. 2012; 8: 445-544.

35. Burn J, Gerdes AM, Macrae F, Mecklin JP, Moeslein G, Olschwang S, Eccles D, Evans DG, Maher ER, Bertario L, Bisgaard ML, Dunlop MG, Ho JW, et al. Long-term effect of aspirin on cancer risk in carriers of hereditary colorectal cancer: an analysis from the CAPP2 randomised controlled trial. Lancet. 2011; 378: 2081-7. https://doi.org/10.1016/ S0140-6736(11)61049-0.

36. Flossmann E, Rothwell PM; British Doctors Aspirin Trial and the UK-TIA Aspirin Trial. Effect of aspirin on longterm risk of colorectal cancer: consistent evidence from randomised and observational studies. Lancet. 2007; 369: 1603-13. https://doi.org/10.1016/S0140-6736(07)60747-8.

37. Rothwell PM, Wilson M, Elwin CE, Norrving B, Algra A, Warlow CP, Meade TW. Long-term effect of aspirin on colorectal cancer incidence and mortality: 20-year follow-up of five randomised trials. Lancet. 2010; 376: 1741-50. https://doi.org/10.1016/S0140-6736(10)61543-7.

38. Goel A, Chang DK, Ricciardiello L, Gasche C, Boland CR. A novel mechanism for aspirin-mediated growth inhibition of human colon cancer cells. Clin Cancer Res. 2003; 9: 383-90.

39. Luciani MG, Campregher C, Gasche C. Aspirin blocks proliferation in colon cells by inducing a G1 arrest and apoptosis through activation of the checkpoint kinase ATM. Carcinogenesis. 2007; 28: 2207-17. https://doi.org/10.1093/ carcin/bgm101.

40. Alfonso LF, Srivenugopal KS, Arumugam TV, Abbruscato TJ, Weidanz JA, Bhat GJ. Aspirin inhibits camptothecininduced p21CIP1 levels and potentiates apoptosis in human breast cancer cells. Int J Oncol. 2009; 34: 597-608.

41. White E. Deconvoluting the context-dependent role for autophagy in cancer. Nat Rev Cancer. 2012; 12: 401-10. https://doi.org/10.1038/nrc3262.

42. Law BY, Chan WK, Xu SW, Wang JR, Bai LP, Liu L, Wong VK. Natural small-molecule enhancers of autophagy induce autophagic cell death in apoptosis-defective cells. Sci Rep. 2014; 4: 5510. https://doi.org/10.1038/srep05510.

43. Ranjan A, Srivastava SK. Penfluridol suppresses pancreatic tumor growth by autophagy-mediated apoptosis. Sci Rep. 2016; 6: 26165. https://doi.org/10.1038/srep26165. 